\title{
A novel method for deriving the aerosol hygroscopicity parameter based only on measurements from a humidified nephelometer system
}

Ye Kuang et al.

Correspondence to: Chunsheng Zhao (zcs@pku.edu.cn)

The copyright of individual parts of the supplement might differ from the CC BY 3.0 License. 


\subsection{Measurement sites}

Datasets from five field campaigns are used in this paper. These campaigns are conducted at four sites on the North China Plain (NCP) during different time periods. The four sites are Wangdu (WD), Xianghe (XH) and Gucheng (GC) in Hebei province and Wuqing (WQ) in Tianjin, and their locations are shown in Fig.S1.

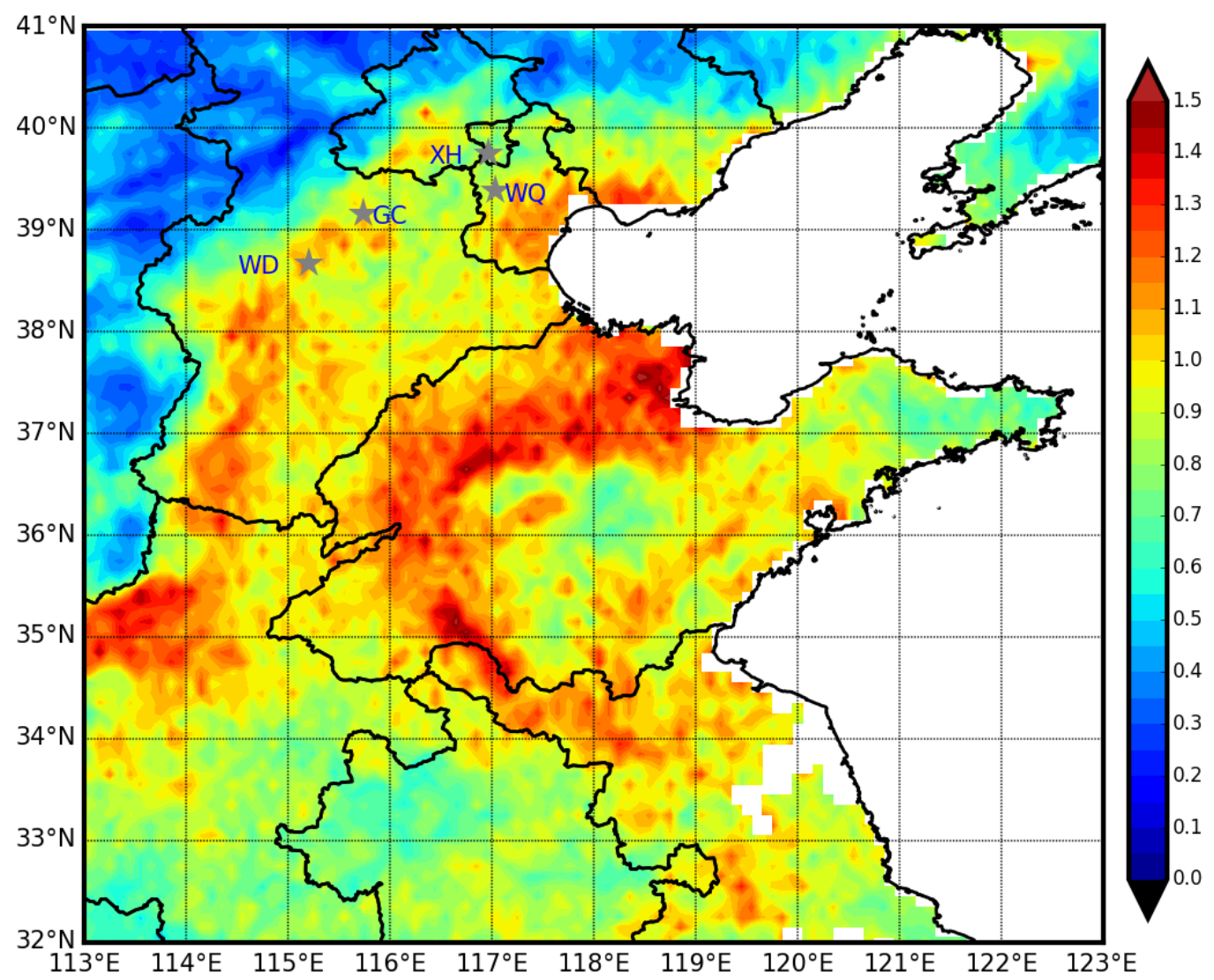

Figure S1. Locations of sites are marked with star markers. Colors represent average distribution of aerosol optical depth at $550 \mathrm{~nm}$ during summer from 2012 to 2014. The dataset of aerosol optical depth at $550 \mathrm{~nm}$ is from Moderate Resolution Imaging Spectroradiometer onboard satellite Aqua.

\subsection{Traditional way of deriving $\kappa_{f(R H)}$ from $\mathrm{f}(\mathrm{RH})$ measurements}




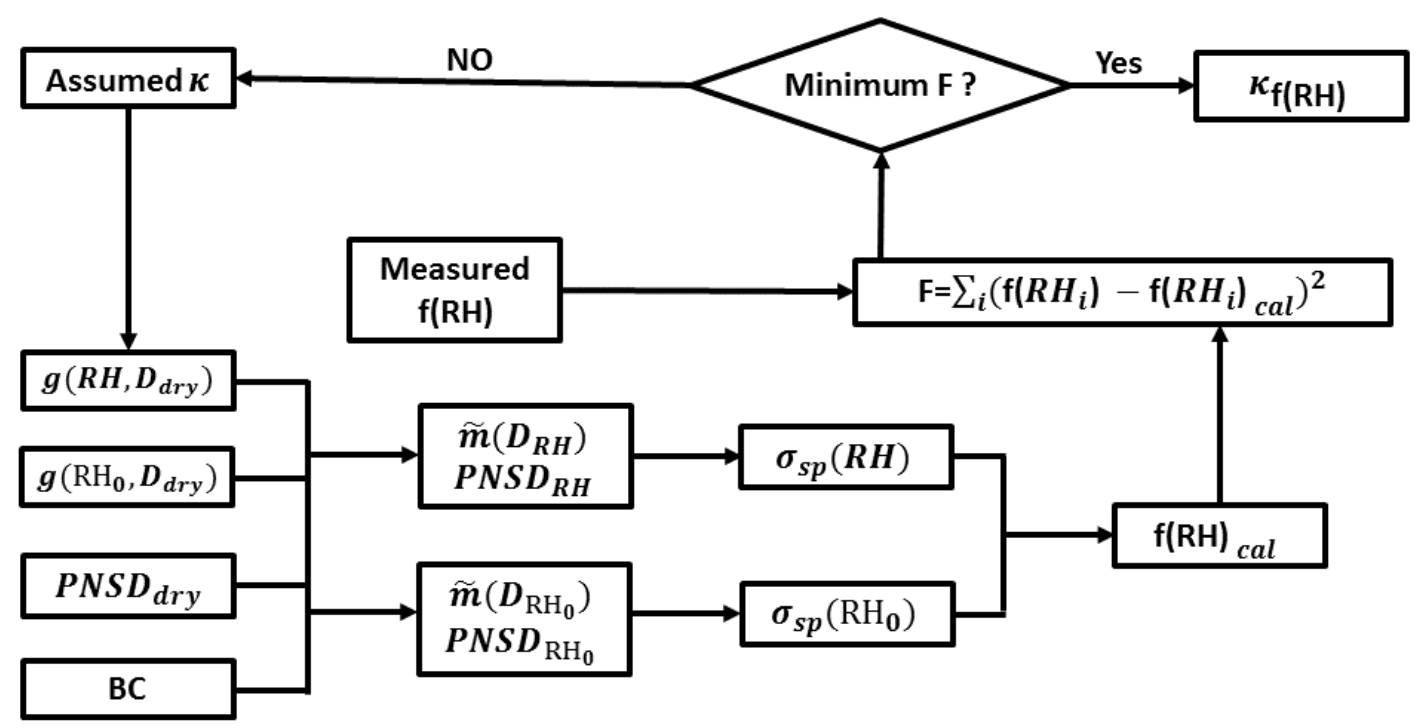

Figure S2. The flow chart of calculating $\kappa_{f(R H)}$ with $\mathrm{f}(\mathrm{RH})$ measurements, PNSD and mass concentration of BC.

The flow chart of deriving $\kappa_{f(R H)}$ from $\mathrm{f}(\mathrm{RH})$ measurements are shown in Fig.S2.

Mass concentration of $\mathrm{BC}$ is distributed to different particle diameters with a fixed mass size distribution of BC which is provided by Ma et al. (2012). The $\widetilde{m}$ represents refractive index. $R H_{0}$ is the sample $\mathrm{RH}$ of the dry nephelometer. The $\widetilde{m}\left(D_{R H}\right)$ can be calculated using the following formula: $\tilde{m}\left(D_{R H}\right)=f_{\text {non-BC }} \cdot \widetilde{m}_{n o n-B C}+f_{B C} \cdot \widetilde{m}_{B C}+$ $f_{\text {water }} \cdot \widetilde{m}_{\text {water }}$, where $f_{\text {non }-B C}, f_{B C}$ and $f_{\text {water }}$ represent the volume fractions of non-BC components, $\mathrm{BC}$ and water. Values of $\widetilde{m}_{n o n-B C}, \widetilde{m}_{B C}$ and $\widetilde{m}_{\text {water }}$ are introduced in the manuscript.

Ma, N., Zhao, C. S., Müller, T., Cheng, Y. F., Liu, P. F., Deng, Z. Z., Xu, W. Y., Ran, L., Nekat, B., van Pinxteren, D., Gnauk, T., Müller, K., Herrmann, H., Yan, P., Zhou, X. J., and Wiedensohler, A.: A new method to determine the mixing state of light absorbing carbonaceous using the measured aerosol optical properties and number size distributions, Atmos. Chem. Phys., 12, 2381-2397, 10.5194/acp-12-2381-2012, 2012. 